\title{
GENERATION OF UNDERWATER OBJECT MOTION BY INTERNAL INTERACTIONS
}

\author{
Janis Viba ${ }^{1}$, Igors Tipans ${ }^{1}$, Willjams Megill ${ }^{2}$, Frederike Oetker ${ }^{2}$ \\ ${ }^{1}$ Riga Technical University, Latvia; ${ }^{2}$ Rhine-Waal University of Applied Sciences, Germany \\ janis.viba@rtu.lv, igors.tipans@rtu.lv, william.megill@hochschule-rhein-waal.de
}

\begin{abstract}
The paper analyses the closed frame object translated motion in the horizontal directions interacting with the fluid (air or water). The object consists of two rigid bodies, fastened together with each other by a spring. The first small body is located inside the large second body, which is isolated from the fluid. As a motion generator internal harmonica or adaptive force control is used. The case is investigated where internal interactions can be with collisions. External interaction of the second body with the fluid flow is nonlinear like absolute velocity in square. Additionally, different drag coefficients are used, depending on the velocity direction of the large body. It is assumed that there is a laminar fluid flow. A system with two or three degrees of freedom is investigated. Interaction with fluids is approximated by a square resistance force dependence on the flow relative velocity taking into account the direction of motion. The resulting system of equations is used to simulate the motion by two programs: Mathcad and Working Model 2D. The three tasks of motion are analysed: - motion with harmonica internal interaction by Mathcad; - motion with adaptive internal interaction by Mathcad; - motion with harmonica internal interaction by Working Model 2D. Some results of the object part motion graphics are given. The main conclusion of the given results is that it is possible to generate closed object motion inside fluid by motion control of another internal body. The results of the investigations can be used for synthesis of new propulsion systems.
\end{abstract}

Keywords: underwater object, variable drag resistance, impact interactions, motion control.

\section{Introduction}

The model of the investigated system is shown in Fig. 1. It consists of two rigid bodies 1 and 2, connected by a spring 3 and a damper 7. Special parameters of the system provide translation motion without rotations. Closed frame object motion inside fluid at low speed region is investigated when the object moves horizontally.

For the system both parts 1 and 2 excitation of internal indirect control action 4 is used (Fig. 1). Additionally, collision interaction is provided by stoppers 6. Outside different drag interactions are provided by the axial elements 5 and 8 .

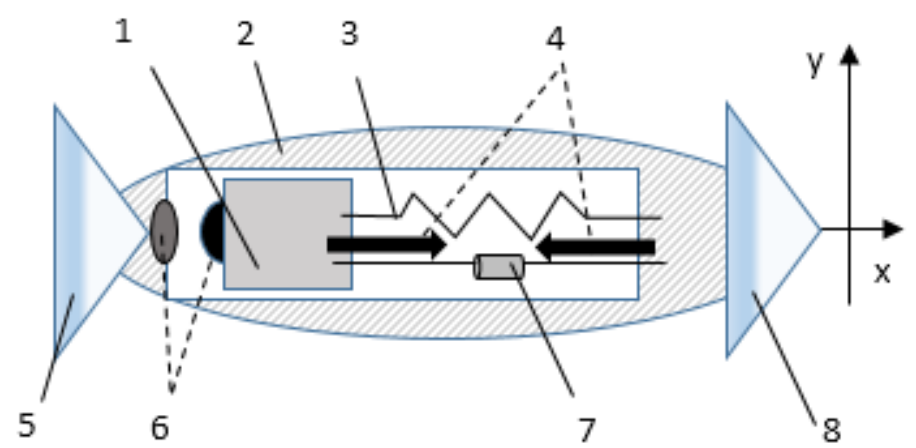

Fig. 1. Object in fluid flow: 1 - small inside body; 2 - closed frame body; 3 - connection spring; 4 - internal control action; 5 - tail element; 6 - collision elements; 7 - damping element; 8 - head element; $x, y$ - longitudinal and transvers axes of object

In object translated motion (without rotation) equation of motion is [1-4]:

$$
m \cdot \bar{a}_{C}=m \cdot \bar{g}+\bar{A}+\bar{R}
$$

where $m$ - total mass of object;

$\overline{a_{C}}-$ acceleration of mass center $C$;

$\bar{g}$ - acceleration of free fall;

$\bar{A}$ - Archimedes force;

$\bar{R}$ - fluid interactions with outside body 2 . 
As the weight $m g$ and Archimedes forces are constant, then from the vector equation (1) it can be concluded that only the force $\bar{R}$ can generate controlled propulsion action and move the object.

\section{Object motion modelling with harmonica internal interaction by Mathcad}

Differential equations of bodies 1 and 2 with mases $\mathrm{m} 1$ and $\mathrm{m} 2$ along horizontal axe are (see (1)):

$$
\begin{aligned}
m 1 \cdot \ddot{x} 1=-c 12 \cdot(x 1-x 2)-b 12 \cdot(v 1-v 2)-[c 0 \cdot(x 1-x 2+\Delta)+ \\
+b 0 \cdot(v 1-v 2)] \cdot[0.5-0.5 \cdot \operatorname{sign}(x 1-x 2+\Delta)]+P 12 \cdot \sin (\omega \cdot t) ; \\
\quad m 2 \cdot \ddot{x} 2=c 12 \cdot(x 1-x 2)+ \\
\quad+b 12 \cdot(v 1-v 2)+[c 0 \cdot(x 1-x 2+\Delta)+ \\
\quad-b 0 \cdot(v 1-v 2)] \cdot[0.5-0.5 \cdot \operatorname{sign}(x 1-v 2+\Delta)]+ \\
\left.\quad-P 12 \cdot \sin (\omega \cdot t)-[D 1-B 1 \cdot \operatorname{sign}(v 2)] \cdot v_{2}^{2} \cdot \operatorname{sign}(v 2)\right],
\end{aligned}
$$

where $c 12-$ stiffness of spring;

$b 12$ - constant of internal damping;

$v 1, v 2$ - velocities of moving mases 1 and 2;

$c 0$ - stiffness of stopper;

$\Delta$ - gap;

$b 0$ - damping of stopper contact force;

$P 12$ - internal action harmonica force amplitude;

$D 1, B 1$ - fluid interactions with outside body 2 (non - symmetric drag coefficients difference) [5-7];

$\omega$ - angular frequency of harmonica force.

Some graphics of modelling by Mathcad in the system SI are shown in Fig. 2-7.

Parameters of modelling in the International System of Units (SI) are:

$c 12=490 ; b 12=4 ; c 0=100 \cdot c 12 ; \Delta=0.05 ; b 0=5 \cdot b 12 ; P 12=20 ; D 1=20 ; B 1=10 ; \omega=60$.

Comments are given under all graphics.

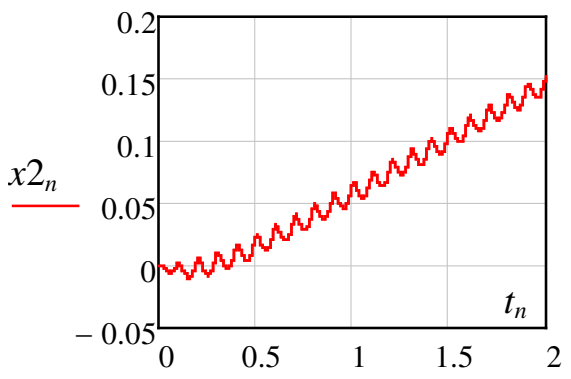

Fig. 2. Motion in time: $t_{n}-$ integration time; $x 2_{n}-$ second body (outside) displacement

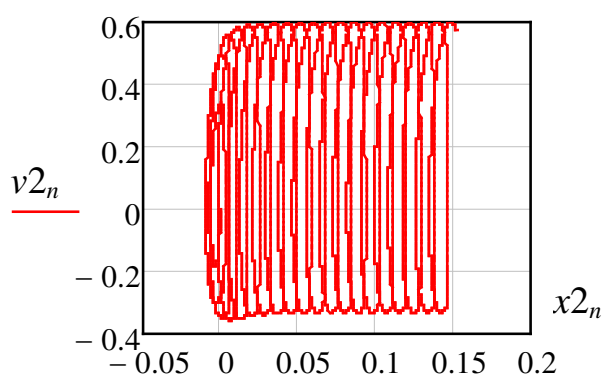

Fig. 4 . Outside body phase plane: $v 2_{n}-$ second body (outside) velocity, motion in phase plane

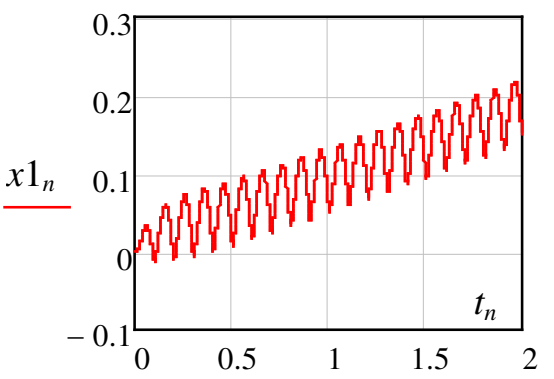

Fig. 3. Object motion in fluid flow: $x 1_{n}$ - first body (inside) displacement

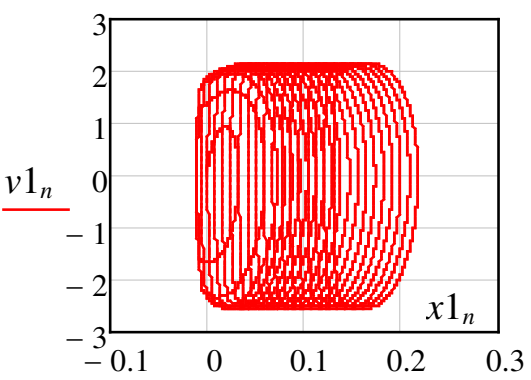

Fig. 5. Inner body phase plane: $v 1_{n}-$ velocity 


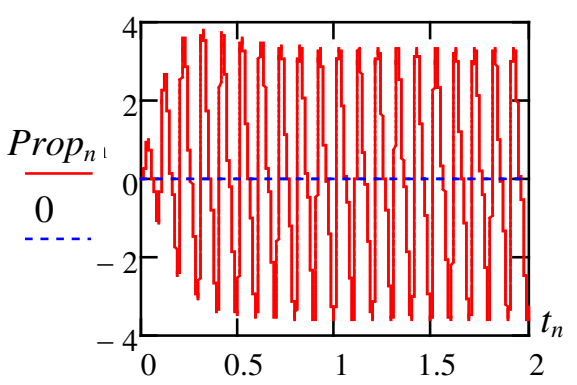

Fig. 6. Object in fluid flow: $\operatorname{Prop}_{n}$ - propulsion force, proportional to velocity in second step

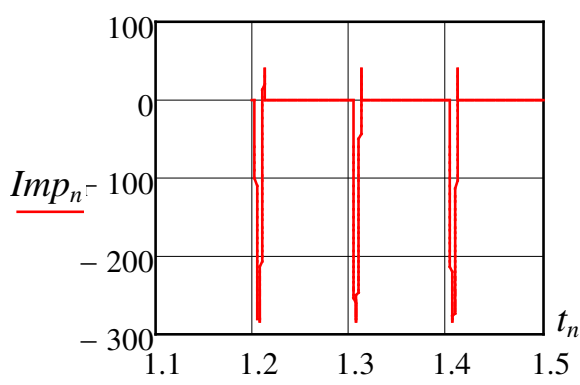

Fig. 7. Collisions: $\operatorname{Imp}_{n}$-impact force between stoppers

\section{Object motion with adaptive interaction by Mathcad}

Differential equations of bodies 1 and 2 with mases $m 1$ and $m 2$ are the same as (2) and (3), with only one difference: instead of two internal time forces $\pm P 12 \cdot \sin (\omega \cdot t)$ adaptive forces $\pm P 12 \cdot \operatorname{sign}(v 1-v 2)$ are used:

$$
\begin{aligned}
& m 1 \cdot \ddot{x} 1=-c 12 \cdot(x 1-x 2)-b 12 \cdot(v 1-v 2)-[c 0 \cdot(x 1-x 2+\Delta)+ \\
& +b 0 \cdot(v 1-v 2)] \cdot[0.5-0.5 \cdot \operatorname{sign}(x 1-x 2+\Delta)]+P 12 \cdot \operatorname{sign}(v 1-v 2) ; \\
& \quad m 2 \cdot \ddot{x} 2=c 12 \cdot(x 1-x 2)+ \\
& \quad+b 12 \cdot(v 1-v 2)+[c 0 \cdot(x 1-x 2+\Delta)+ \\
& \quad-b 0 \cdot(v 1-v 2)] \cdot[0.5-0.5 \cdot \operatorname{sign}(x 1-x 2+\Delta)]+ \\
& \left.\quad-P 12 \cdot \operatorname{sign}(v 1-v 2)-[D 1-B 1 \cdot \operatorname{sign}(v 2)] \cdot v_{2}^{2} \cdot \operatorname{sign}(v 2)\right] .
\end{aligned}
$$

where $P 12 \cdot \operatorname{sign}(v 1-v 2)$ - adaptive internal force, depending on the relative velocity direction $\operatorname{sign}(v 1-v 2)$, but other parameters are the same.

Some graphics of modelling are shown in Fig. 8-12. Comments are given under all graphics.

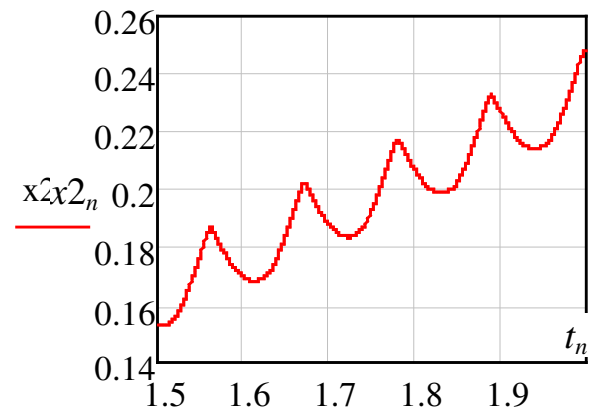

Fig. 8. Displacement of mass $\mathbf{m}_{2}$

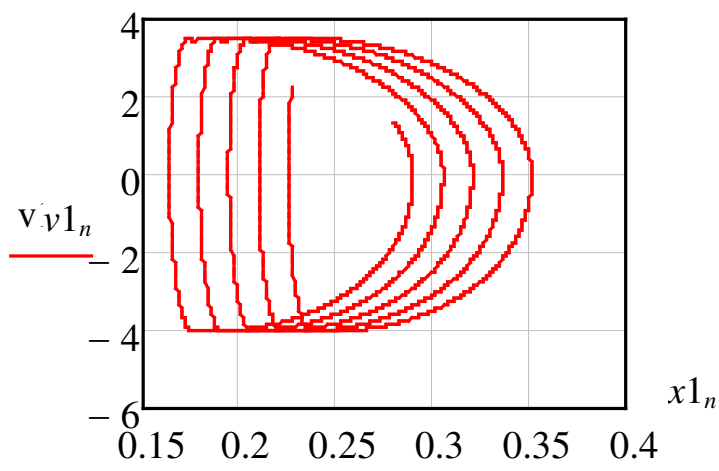

Fig. 10. Motion in phase plain for mass $\mathbf{m}_{1} \quad$ Fig. 11. Object in fluid flow : Pactuat $_{n}-$ two level adaptive inner actuation force $\operatorname{sign}(v 1-v 2)$, see (7) 
Object motion modelling with harmonica interaction by Working Model 2D

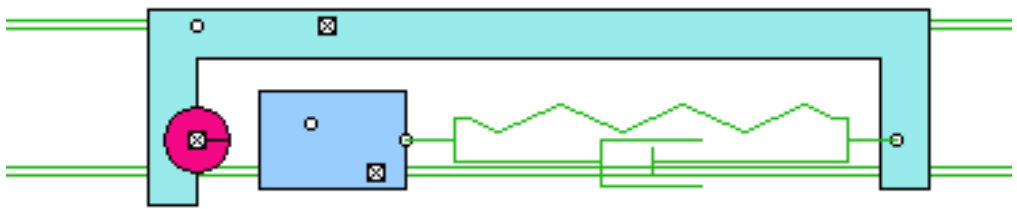

\begin{tabular}{|c|c|}
\hline \multicolumn{2}{|l|}{ Force } \\
\hline$F x-5^{x} \sin \left(5^{x} t\right)$ & $N$ \\
\hline Fy 0.000 & $N$ \\
\hline Force & \\
\hline$F x 5^{\times} \sin \left(5^{\times} t\right)$ & N \\
\hline Fy 0.000 & N \\
\hline
\end{tabular}

Fig. 12. Working Model 2D: Fx - internal indirect forces

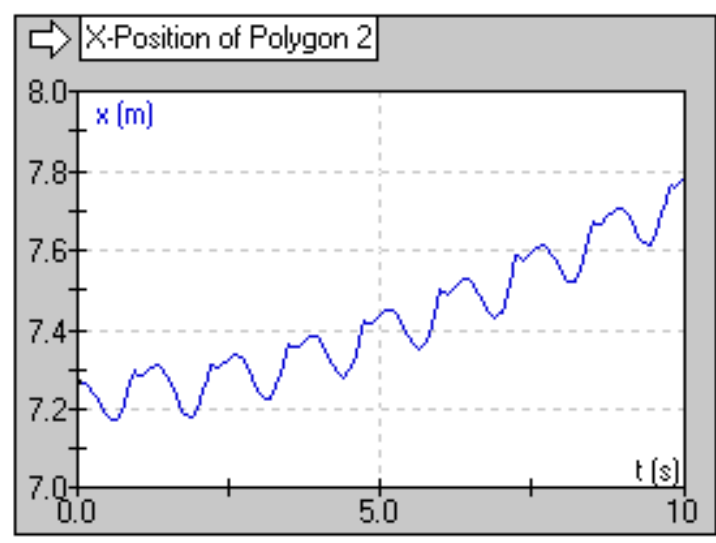

Fig. 13. Mass $\boldsymbol{m}_{2}$ displacement in time $t$

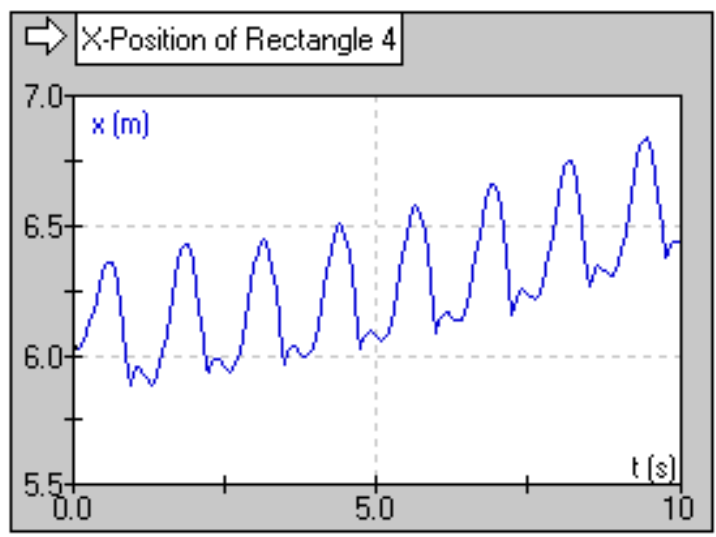

Fig. 15. Mass $\mathbf{m}_{1}$ displacement in time $t$

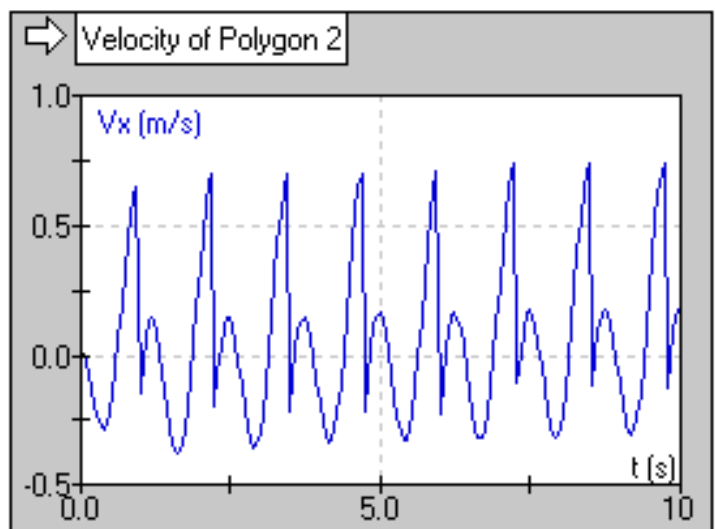

Fig. 14. Mass $\boldsymbol{m}_{2}$ velocity in time $t$

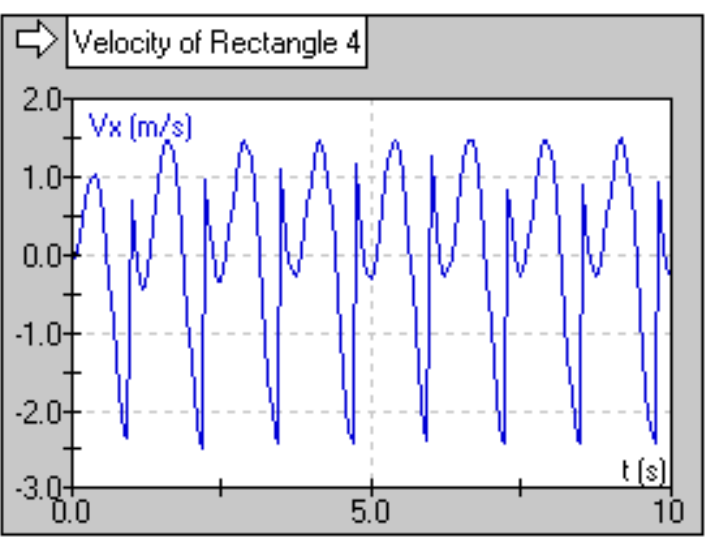

Fig. 16. Mass $\mathbf{m}_{1}$ velocity in time $t$

\section{Results and discussion}

The main results of this report are that possibilities of closed frame object motion inside fluid are obtained. For that reason non symmetric motion (till impacts) of an additional body inside the frame can be used. More efficiency motion according to the maximal velocity can be generated by the adaptive force. The modelling shows that some time (for low velocities) harmonica time force interactions are applicable. The obtained results may be used for robot motion generation inside fluid. The ideas of this investigation are partially used for synthesis of new devices in the patents [8-15]. 


\section{Conclusions}

1. For closed frame objects (without fans or propellers) it is possible to use internal non - linear vibrations for motion generation.

2. More efficiency motion is achieved when different drag coefficients (direct and indirect) are used.

3. The investigated task shows that the motion velocity will be in low region because reverse of interaction force directions exists.

\section{References}

1. Bedford A., Fowler W. Engineering Mechanics; Statics \& Dynamics. 4th ed. Pearson Education, Inc. USA. 2005. $622 \mathrm{p}$.

2. Kepe O., Viba J. Theoretical Mechanics. Riga, 1982, 577 p. (in Latvian).

3. Viba, J. Optimisation and synthesis of vibro impact systems. Riga: Zinatne, 1988. 253 p. (in Russian).

4. Payne, L. E. and Pell, W. H. The Stokes flow problem for a class of axially symmetric bodies. Journal of Fluid Mechanics, Vol. 7, Issue 04, April, 1960, pp 529-549.

5. Clancy, L. J. Aerodynamics. Publisher by Pitman. New York. London, 1975. 610 p.

6. Morrison, F. A. An Introduction to Fluid Mechanics. New York: Cembridge University Press, 2013. $625 \mathrm{p}$.

7. Faith A. Morrison F. A. Data Correlation for Drag Coefficient for Sphere. Department of Chemical Engineering Michigan Technological University, Houghton, MI 49931. Available at: http://www.chem.mtu.edu/ fmorriso/DataCorrelationForSphereDrag2013.

8. Patent LV 14237, Republic of Latvia, Int.Cl. B63 H1/00. Hydrodynamic fin-type vibration propulsive device / S. Cifanskis, J. Viba, V. Beresnevich, V. Jakushevich, J.-G. Fontaine, W. Megill. - Applied on 07.10.2010, application P-10-141; published 20.02.2011 // Patenti un preču zìmes, 2011, No. 2, p. 188.

9. Patent LV 14289, Republic of Latvia, Int.Cl. B63 H1/00. Hydrodynamic fin-type vibration propulsive device / S. Cifanskis, V. Beresnevich, J. Viba, V. Jakushevich. - Applied on 17.01.2011, application P-11-05; published 20.05.2011 // Patenti un preču zīmes, 2011, No. 5, p. 656.

10. Patent LV 14322, Republic of Latvia, Int.Cl. B63 H1/00. Vibrating actuator of the robot-fish / S. Cifanskis, J. Viba, V. Jakushevich. - Applied on 25.02.2011, application P-11-24; published 20.09.2011 // Patenti un preču zìmes, 2011, No. 9, p. 1288.

11. Patent LV 14323, Republic of Latvia, Int.Cl. B63 H1/00. Hydrodynamic vibrating actuator of fin / S. Cifanskis, J. Viba, V. Jakushevich. - Applied on 03.03.2011, application P-11-27; published 20.09.2011 // Patenti un preču zìmes, 2011, No. 9, p. 1288 - 1289.

12. Hidrodinamiskā spuras vibrokustinātāja pārneses mehānisms. S. Cifanskis, J. Vība, V. Jakuševičs. Patents LV 14363, Latvijas Republika, Int. Cl B63H1/00, no 21.04.2011.

13. Hidrodinamiskais spuras vibrokustinātājs. S. Cifanskis, J. Vība, O Kononova. Patents LV 14385, Latvijas Republika, Int. Cl B63H1/00, no 10.06.2011.

14. Patent LV 14386, Republic of Latvia, Int.Cl. B63 H1/00. Gyroscopic method for forming motive force of floating vehicle / J. Viba, J. Auzins, V. Beresnevich, S. Cifanskis, I. Kaktabulis, G. Kulikovskis, I. Tipans, A. Melnikovs, M. Kruusmaa, W. Megill. - Applied on 14.06.2011, application P-11-84; published 20.12.2011 // Patenti un preču zìmes, 2011, No. 12, p. 1774.

15. Patent LV 14428, Republic of Latvia, Int.Cl. B63 G8/14. Device for regulation of buoyancy of object floating under water / S. Cifanskis, J. Viba, V. Jakushevich. - Applied on 29.09.2011, application P-11-127; published 20.01.2012 // Patenti un preču zīmes, 2012, No. 1, p. 17. 